\title{
POTENCIAIS HÍDRICOS E TEORES DE ÁGUA NA GERMINAÇÃO DE SEMENTES E CRESCIMENTO INICIAL DE MILHETO
}

\author{
TATHIANA ELISA MASETTO ${ }^{1}$, ELIZANGELA LEITE VARGAS ${ }^{1}$ \\ e SILVANA DE PAULA QUINTÃO SCALON ${ }^{1}$
}

\author{
${ }^{1}$ Universidade Federal da Grande Dourados, Faculdade de Ciências Agrárias, Cidade Universitária, \\ Caixa Postal 533, CEP: 79804-970,Dourados-MS tathianamasetto@ufgd.edu.br, \\ elileitevargas@gmail.com,silvanascalon@ufgd.edu.br
}

Revista Brasileira de Milho e Sorgo, v.15, n.3, p. 619-630, 2016

\begin{abstract}
RESUMO - O processo germinativo se inicia com a absorção de água pelas sementes e é influenciado pela disponibilidade hídrica e pelo teor de água das sementes. Objetivou-se avaliar os efeitos de diferentes potenciais hídricos e de teores de água das sementes na germinação e crescimento de plântulas de milheto. Foram utilizadas sementes com teores de água de $14,1 \% ; 16,1 \% ; 20,8 \%$ e 21,9\% posicionadas em caixas plásticas do tipo "gerbox" sobre duas folhas de papel toalha para germinação previamente umedecidas com $10 \mathrm{~mL}$ de soluções de polietilenoglicol (PEG 6000) nos potenciais hídricos de 0,$0 ;-0,1 ;-0,2 ;-0,3 ;-0,4$ e - $0,6 \mathrm{MPa}$. As sementes foram mantidas em câmara de germinação a $25{ }^{\circ} \mathrm{C}$ sob luz branca constante. $\mathrm{O}$ delineamento experimental foi o inteiramente casualizado, em esquema fatorial 4 x 5, utilizando-se quatro repetições de 50 sementes cada. As sementes foram avaliadas quanto à primeira contagem, germinação, comprimento da raiz, comprimento da parte aérea, comprimento total, massa fresca e seca de plântulas. A redução dos potenciais hídricos associada aos teores de água das sementes afeta negativamente a germinação e o crescimento das plântulas de milheto, principalmente em sementes com o teor de água de 14,1\%. As sementes com os teores de água acima de $16,1 \%$ são menos suscetíveis à redução das disponibilidades hídricas do substrato a partir do potencial de -0,1 MPa.
\end{abstract}

Palavras-chave: Pennisetum glaucum, polietilenoglicol, teor de água de sementes.

\section{WATER POTENTIAL AND MOISTURE CONTENT ON SEED GERMINATION AND INITIAL GROWTH OF PEARL MILLET}

\begin{abstract}
The germination process starts with water absorption by seeds and is influenced by the water availability and seeds moisture content. This work aimed to evaluate the effects of different substrate water potentials and the water contents of the seeds on seed germination of pearl millet. The treatments comprised pearl millet seeds with $14.1 \%$, $16.1 \%, 20.8 \%$ and $21.9 \%$ moisture content and submitted to the water availability in the substrate of 0.0 (control); -0.1 ; $-0.2 ;-0.3 ;-0.4$ and -0.6 MPa. Seeds were sowed in two germination papers and positioned inside plastic boxes of the "gerbox" type and maintained at $25^{\circ} \mathrm{C}$. A completely randomized design in a factorial scheme $4 \mathrm{x} 5$ was used, with four replications of 50 seeds per treatment. The seeds were evaluated through the first counting, germination percentage, aerial part, root length, total length and fresh and dry mass of seedlings. The reduction of the water potentials associated to the seed water contents affected negatively the seeds germination and seedlings growth of pearl millet, especially in seeds with $14.1 \%$ water content. The seeds with water content above $16.1 \%$ were less sensitive to the decrease in the water availability of the substrate from $-0.1 \mathrm{MPa}$.
\end{abstract}

Keywords: Pennisetum glaucum, polyethylene glycol, seeds water content. 
O milheto (Pennisetum glaucum (L.) expandiuse na região Centro-Oeste, constituindo uma das formas de integração lavoura-pecuária, sendo utilizado para pastejo, como cobertura vegetal no plantio direto, produção de grãos, além da possibilidade de ser utilizado como silagem (Bergamaschine et al., 2011). É altamente recomendado como forrageira e para produção de grãos em ambientes áridos e semiáridos (Yadav \& Singh, 2012) e apresenta alta adaptabilidade nas condições do Cerrado brasileiro, onde o nível de fertilidade é baixo e o período de estiagem prolongado (Pereira Filho et al., 2003). Entretanto, foi verificado que o estresse hídrico severo durante todo o período de estabelecimento da cultura afetou os crescimentos de parte aérea e radicular das plantas de milheto, ocasionando redução da biomassa forrageira (Kusaka et al., 2005).

A falta de disponibilidade de água durante longos períodos pode interferir na produtividade das culturas e limitar as áreas agricultáveis (Fagundes et al., 2010). Além disso, as previsões ambientais sinalizam para episódios com restrições hídricas cada vez mais frequentes (Intergovernmental Panel on Climate Change, 2014), caracterizando a tolerância à seca como uma das necessidades para a competitividade das culturas e estimulando, assim, estudos sobre o processo germinativo e estabelecimento das culturas sob condições de baixa disponibilidade hídrica, que poderão fornecer subsídios para a manutenção da produção agrícola. Santos et al. (2011) ressaltam que o entendimento da tolerância das plantas à seca e como explorá-las, principalmente com relação aos problemas de ordem fisiológica, apresenta extrema importância, sobretudo para recuperação de áreas onde há problemas com estresse hídrico por razões climáticas ou condições do tipo de solo.

A disponibilidade de água é o fator ambiental preponderante na germinação das sementes e sua li- mitação provoca atraso no início do processo ou diminui a porcentagem de germinação (Waterworth et al., 2015). O processo germinativo se inicia com a absorção de água; porém, é necessário que a semente alcance um nível adequado de hidratação, o qual permita a retomada do crescimento do embrião que havia sido paralisado durante a maturação das sementes.

O estudo da germinação de sementes sob estresse hídrico tem grande aplicabilidade no manejo das culturas, sendo que para cada espécie existe um patamar de potencial hídrico no solo, abaixo do qual a germinação não ocorre (Bewley \& Black, 1994). A simulação de um ambiente em condições de estresse hídrico é possível com a utilização de agentes osmóticos, como o polietilenoglicol (PEG), que é um dos produtos mais utilizados para simular a redução da disponibilidade hídrica nas fases iniciais da germinação de sementes de plantas forrageiras como Sorghum bicolor (Oliveira \& Gomes-Filho, 2009) e Urochloa ruziziensis (Masetto et al., 2013), pois tem a vantagem de ser inerte e promove a deficiência hídrica sem penetrar no tegumento das sementes.

Além da disponibilidade hídrica a que as sementes estão sujeitas, a absorção de água inicial (embebição) pode ser influenciada pelo teor de água que as sementes apresentam. A entrada e a distribuição da água nas sementes, reguladas pelo potencial hídrico, ocorrem tanto por capilaridade como por difusão, no sentido do maior para o menor potencial (Silva \& Villela, 2011). Nesse contexto, sementes muito secas, ao entrarem em contato com a água, podem apresentar taxa de absorção de água muito elevada, proporcionando a ocorrência de eventuais danos por embebição que são responsáveis pela diminuição da velocidade de germinação das sementes e que, possivelmente, não ocorreriam em sementes com teor de água mais elevado. 
Embora a restrição hídrica em espécies vegetais tenha sido estudada em vários aspectos fisiológicos, com o cenário iminente de disponibilidade hídrica cada vez mais escassa, principalmente em regiões tropicais, existe a necessidade de se expandir o conhecimento básico sobre a germinação das sementes em condições de disponibilidade hídrica. Apesar de mostrar ampla capacidade de adaptação, um melhor conhecimento das características da planta de milheto é fator importante para a expansão e o aproveitamento correto da cultura, pois o seu comportamento pode variar em função das diferentes condições ambientais (Coimbra \& Nakagawa, 2006).

Devido à utilização do milheto nas regiões de Cerrado em períodos sujeitos à estiagem e em áreas agrícolas com baixa disponibilidade de água, objetivou-se com este trabalho estudar o comportamento das sementes com diferentes teores de água submetidas a diferentes potenciais hídricos do substrato com soluções de PEG.

\section{Material e Métodos}

O experimento foi realizado no Laboratório de Sementes da Faculdade de Ciências Agrárias (FCA) da Universidade Federal da Grande Dourados (UFGD), em Dourados, MS, Brasil. Foram utilizadas sementes de milheto cv. BRS 1501, safra 2012/2013, produzidas em Mato Grosso do Sul. Após a colheita, as sementes permaneceram no interior de sacos de papel Kraft e acondicionadas na câmara fria e seca do laboratório $\left(16 \pm 1{ }^{\circ} \mathrm{C} / 40 \%\right.$ umidade relativa) durante cinco dias. $\mathrm{O}$ teor de água das sementes foi determinado pelo método da estufa a $105 \pm 3{ }^{\circ} \mathrm{C}$, durante 24 $\mathrm{h}$, utilizando-se quatro repetições, conforme a metodologia prescrita nas Regras para Análise de Sementes (RAS) (Regras..., 2009).
Para avaliar o efeito do teor de água das sementes associado à disponibilidade hídrica do substrato, obtiveram-se sementes com diferentes teores de água, adotando-se o procedimento de umedecimento artificial da seguinte forma: foram empregadas caixas plásticas transparentes do tipo "gerbox" (11 x $11 \mathrm{x}$ $3,5 \mathrm{~cm}$ ) contendo $40 \mathrm{~mL}$ de água destilada no fundo e as sementes foram distribuídas sobre as telas de alumínio posicionadas no interior de cada uma das caixas. As caixas foram tampadas e mantidas em câmaras do tipo B.O.D. reguladas a $25^{\circ} \mathrm{C}$. Durante a permanência das caixas na câmara, foi realizado, periodicamente, o monitoramento da massa úmida das sementes em hidratação, por meio de sucessivas pesagens, adotando-se como referência o teor de água inicial de $14,1 \%$ até serem atingidos os teores de água de $16,1 \%, 20,8 \%$ e $21,9 \%$.

Posteriormente, as sementes foram desinfestadas com solução de hipoclorito de sódio a 2,5\% durante $2 \mathrm{~min}$. Em seguida, foram dispostas uniformemente no interior de caixas plásticas do tipo "gerbox" forradas com duas folhas de papel germitest previamente umedecidas com água destilada ao equivalente a 2,5 vezes a massa do papel seco. Para a obtenção dos potenciais hídricos de - 0,$1 ;-0,2 ;-0,3 ;-0,4$ e $-0,6$ $\mathrm{MPa}$, foram utilizadas as quantidades de polietilenoglicol (PEG) (6000) de 80;120;150; 175 e 225 $\mathrm{g} \mathrm{kg}^{-1}$ de água destilada, respectivamente, preparados segundo Michel e Kaufmann (1973). Foram utilizados $10 \mathrm{~mL}$ das soluções aquosas de PEG (6000) para o umedecimento dos substratos. As caixas plásticas com as sementes foram mantidas em B.O.D. a $25{ }^{\circ} \mathrm{C}$ sob luz branca constante.

O efeito de diferentes teores de água e de disponibilidades hídricas foi avaliado por meio dos seguintes testes: primeira contagem - as avaliações foram efetuadas no terceiro dia após o início do teste, 
de acordo com os critérios estabelecidos pelas RAS (Regras..., 2009). Germinação - avaliada no sétimo dia após a instalação do teste, computando-se a porcentagem de plântulas normais (Regras..., 2009). Comprimento de plântulas - foram utilizadas quatro repetições com dez sementes posicionadas no terço superior do papel para cada tratamento, sendo determinados comprimento da raiz primária (CR), comprimento de parte aérea (CPA), tomando-se do ápice da plântula até a inserção da raiz, e o comprimento total das plântulas (CT). As medidas foram determinadas com régua graduada em milímetros e os resultados foram expressos em cm plântula ${ }^{-1}$. Massa de plântulas - foi determinada pela massa fresca e seca de dez plântulas inteiras pesadas em balança analítica com quatro casas decimais. Para se obter a massa seca, as plântulas foram colocadas em saco de papel no interior de estufa com ventilação forçada de ar regulada a $65{ }^{\circ} \mathrm{C}$ até obter massa constante. Os resultados foram expressos em g plântula ${ }^{-1}$.

O delineamento experimental foi o inteiramente casualizado, em esquema fatorial 4 x 5 (teores de água e potenciais hídricos do substrato), com quatro repetições de 50 sementes cada. Os resultados foram submetidos à análise de variância pelo teste $\mathrm{F}$, a 5\% de probabilidade e quando significativos foram submetidos à análise de regressão, utilizando o programa estatístico Sisvar (Ferreira, 2011).

\section{Resultados e Discussão}

A primeira contagem de germinação de sementes de milheto não foi influenciada significativamente pela redução dos potenciais hídricos do substrato e pelos teores de água das sementes. As sementes com teor de água de $14,1 \%$ apresentaram resultado médio de $26 \%$ de germinação na primeira contagem e as sementes com os teores de água de 16,1\%,20,8\% e $21,9 \%$ apresentaram resultados médios de 31,29 e 24\% de germinação (Figura 1).

Houve efeitos significativos dos potenciais hídricos e dos teores de água sobre a germinação das sementes, sendo verificados efeitos prejudiciais da redução dos potenciais hídricos em sementes de mi-

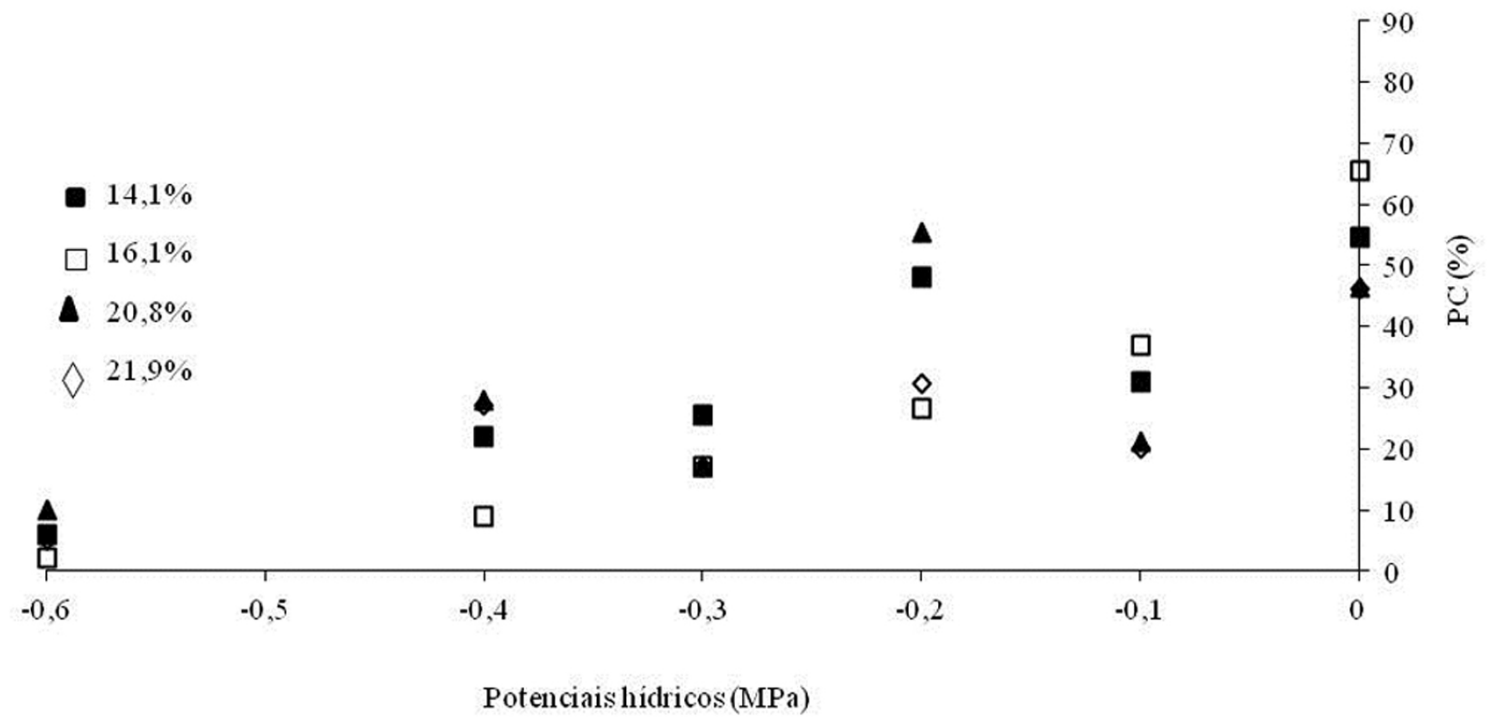

Figura 1. Primeira contagem (PC\%) de germinação de sementes de milheto com diferentes teores de água e submetidas a diferentes potenciais hídricos com soluções de PEG 6000. Dourados, MS, 2016. 
lheto (Figura 2). As sementes com os teores de água de $14,1 \%, 16,1 \%, 20,8 \%$ e $21,9 \%$ apresentaram porcentagens de germinação de $77 \%, 70 \%, 50 \%$ e $61 \%$, respectivamente (Figura 2); porém, com a redução dos potenciais hídricos, observou-se que as sementes com o teor de água de $14,1 \%$ apresentaram resultado mínimo no potencial de $-0,55 \mathrm{MPa}$, sendo que as sementes com os teores de água de $16,1 \%, 20,8 \%$ e $21,9 \%$ apresentaram resultados mínimos de germinação nos potenciais de -2,04, -0,09 e -0,86 MPa, respectivamente. A diminuição da germinação também pode ser atribuída a menor mobilização das reservas, menor síntese e atividade enzimática ou mudanças na turgescência celular (Bewley \& Black, 1994) em condições de redução da disponibilidade hídrica.

Vale salientar que as sementes com os teores de água de 14,1\% apresentaram redução mais acentuada da germinação com a redução da disponibilidade hídrica, indicando que, quanto menor o teor de água, maior é a suscetibilidade que as sementes apresentam às limitações da disponibilidade hídrica causada pelo aumento das concentrações de PEG. Estes resultados sugerem que o teor de água acima de $16 \%$ pode desempenhar uma função no sentido de facilitar a embebição e a retenção de água pelas sementes de milheto sob condições de estresse hídrico.

Os efeitos prejudiciais da restrição hídrica na germinação das sementes também foram verificados em sementes de milho pipoca submetidas às condições de estresse hídrico causado por soluções de PEG abaixo de -0,4 MPa, sendo que a diminuição desta característica pode ser atribuída ao direcionamento do metabolismo a contornar essas condições; com isso, o gasto energético é maior com relação à adaptação ao estresse do que à germinação propriamente dita (Vaz-de-Melo et al., 2012).

Possivelmente, existe uma variação quanto ao teor de água de sementes em relação aos limites de tolerância ao estresse hídrico durante a fase de germinação, determinando a importância da umidade da semente no controle da germinação. Nesse sentido, a influência do teor de água das sementes sobre a germinação pode variar de acordo com a espécie:

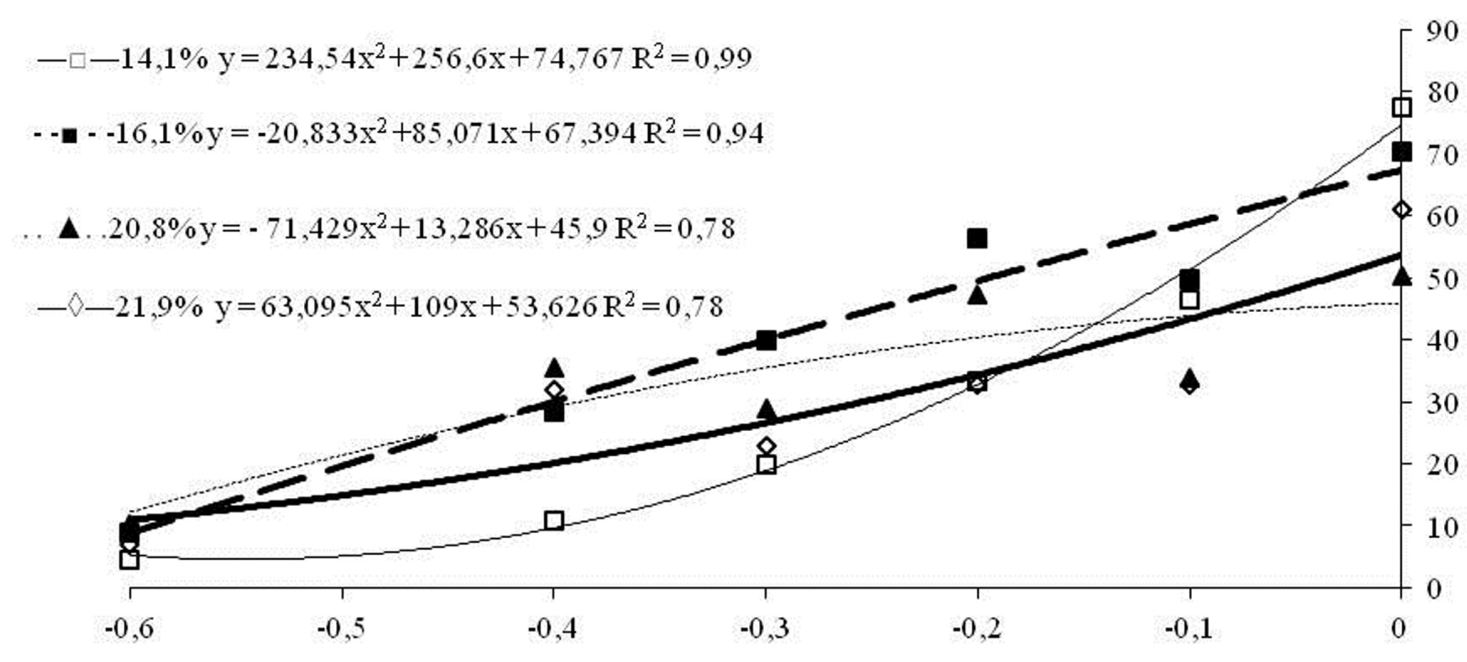

Potencial hidrico (MPa)

Figura 2. Porcentagem de germinação $(\mathrm{G} \%)$ de sementes de milheto com diferentes teores de água e submetidas a diferentes potenciais hídricos do substrato com soluções de PEG. Dourados, MS, 2016. 
em sementes mutantes de Arabidopsis thaliana sem os polissacarídeos depositados no tegumento responsáveis pela formação de uma mucilagem (que promove a umidade controlando a embebição de água), ocorre redução da germinação em meio osmótico com PEG (Penfield et al., 2001); sementes de feijão (Phaseolus vulgaris) com teores de água de 9 , 11 e 13\% apresentaram redução crescente da germinação à medida que as disponibilidades hídricas foram sendo reduzidas a partir de -0,04 MPa com PEG (Forti et al., 2009); em sementes de Urochloa ruziziensis, a extensão dos danos provocados na germinação e no crescimento de plântulas deve-se à severidade do estresse hídrico causado por PEG e ao teor de água de 9,5\% nas sementes (Masetto et al., 2013).

Houve efeitos significativos dos teores de água e dos potenciais hídricos do substrato sobre o comprimento de parte aérea de plântulas (Figura 3). Com a diminuição dos potenciais hídricos do substrato, houve redução do crescimento das plântulas de milheto provenientes de sementes com diferentes teores de água e verificou-se que as sementes com teores de água de $16,1 \%$ e $21,9 \%$ apresentam resultado mínimo nos potenciais de $-1,39$ e $-0,95 \mathrm{MPa}$, respectivamente, sendo que as sementes com o teor de água de 14,6\% apresentaram comprimento mínimo já no potencial de -0,9 MPa (Figura 3). Segundo Bonfim-Silva et al. (2011), a área foliar é uma característica relevante no desenvolvimento inicial das gramíneas, pois as folhas são a fonte de fotoassimilados para as raízes, que por sua vez participam da assimilação de nutrientes e são importantes na resistência ao déficit hídrico. Nesse sentido, a redução do comprimento de parte aérea em plantas sob estresse hídrico pode ser considerada uma estratégia de sobrevivência para evitar a perda de água por transpiração (Correia \& Nogueira, 2004).

Observou-se que o crescimento de raiz (CR) e o crescimento total de plântulas (CT) foram influenciados significativamente somente pelos potenciais hídricos do substrato, sendo verificados resultados mínimos nos potenciais de -1,16 MPa e -0,74 MPa, respectivamente (Figuras 4 e 5). Esses resultados su-

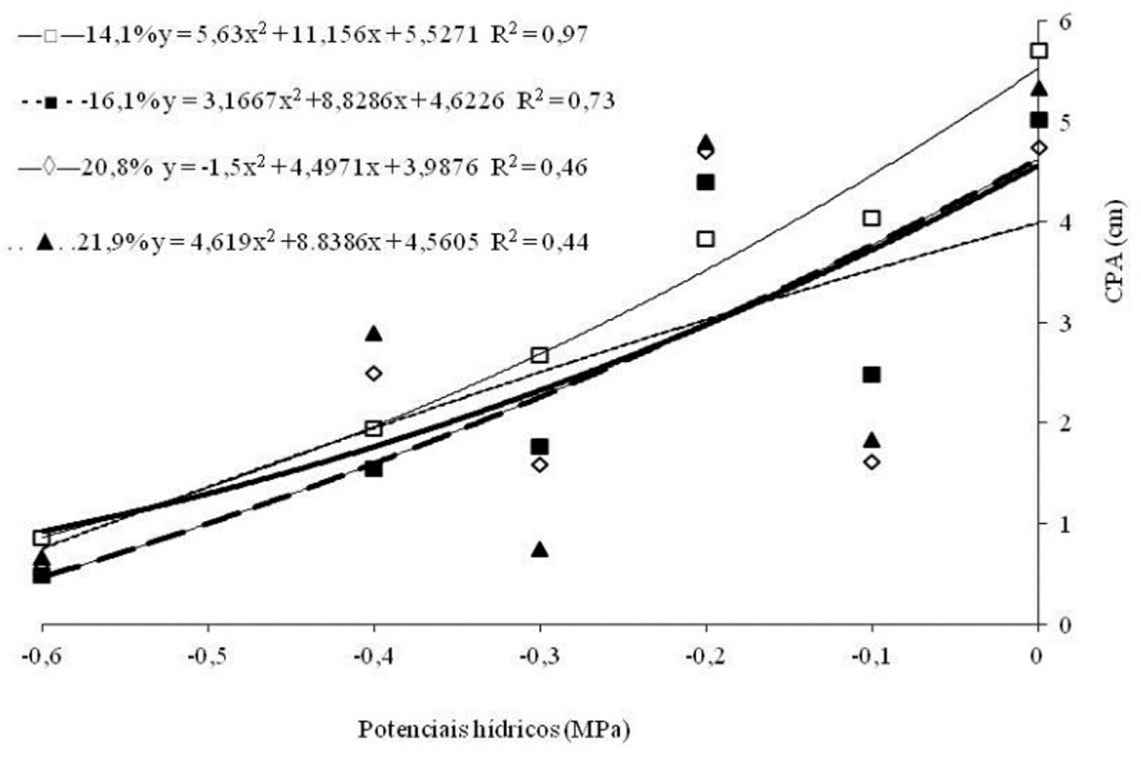

Figura 3. Comprimento de parte aérea (CPA) de sementes de milheto com diferentes teores de água e submetidas a diferentes potenciais hídricos do substrato com soluções de PEG. Dourados, MS, 2016. 
gerem que os crescimentos geral da plântula e, sobretudo, da raiz foram afetados pela disponibilidade hídrica e que não ocorre a influência dos teores de água das sementes, indicando a rusticidade do milheto sob condições de restrição hídrica durante a fase de plântula. De acordo com Gechev et al. (2012), as plantas se adaptam à seca por meio de numerosos mecanismos fisiológicos e morfológicos, sendo que alguns são imediatos ao estresse, como o fechamento estomático governado principalmente por ácido abcísico (ABA). Entretanto, mudanças na arquitetura radicular, como o crescimento de raízes em resposta ao estresse hídrico, estão associadas à redução do crescimento da parte aérea. Nesse contexto, a redução no comprimento total de plântulas é ocasionada pelas mudanças na turgescência celular devido à diminuição da síntese de proteínas em condições de estresse hídrico (Dell’Aquila, 1992).

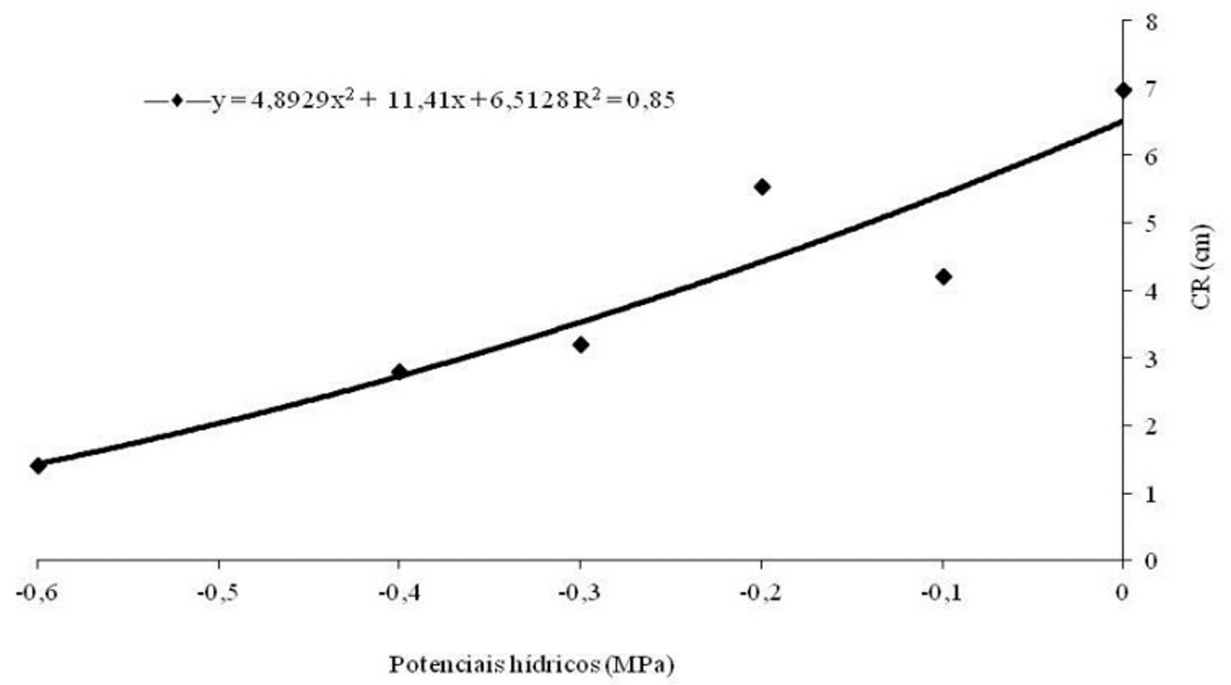

Figura 4. Comprimento da raiz (CR) de plântulas de milheto provenientes de sementes de milheto com diferentes teores de água e submetidas a diferentes potenciais hídricos do substrato com soluções de PEG. Dourados, MS, 2016.

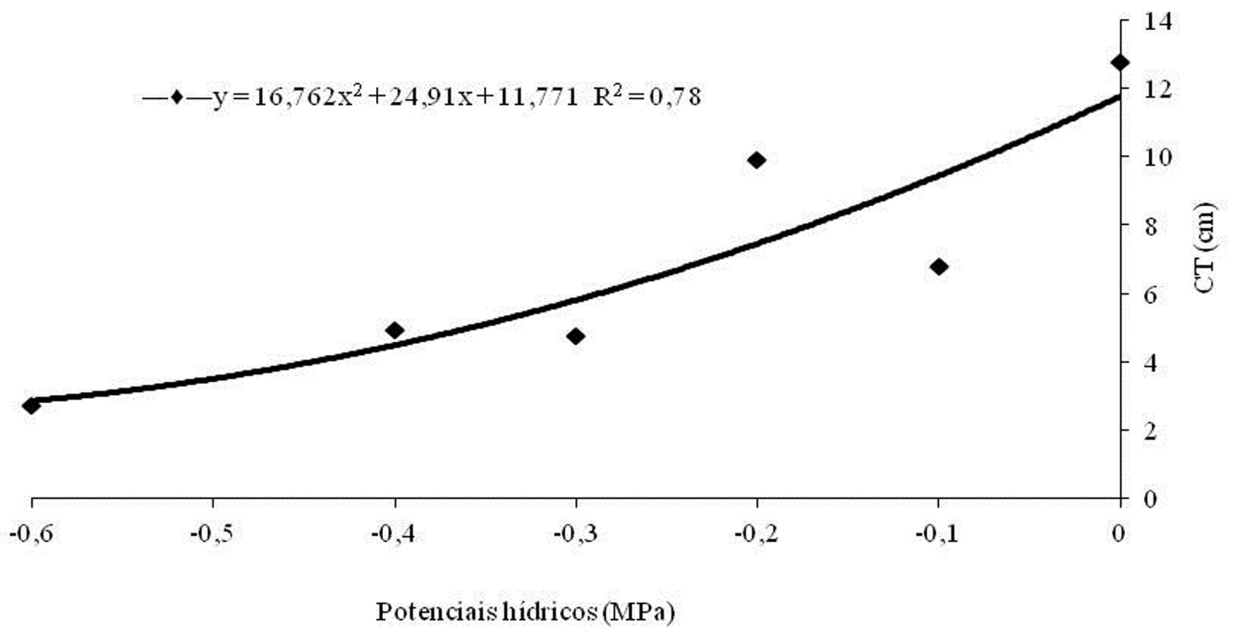

Figura 5. Comprimento total (CT) de plântulas de milheto provenientes de sementes com diferentes teores de água e submetidas a diferentes potenciais hídricos do substrato com soluções de PEG. Dourados, MS, 2016. 
Houve interações significativas entre os teores de água das sementes e os potenciais hídricos para as massas fresca e seca de plântulas, sendo verificado que as sementes com os teores de água de $14,1 \%$, $16,1 \%, 20,8 \%$ e $21,9 \%$ apresentaram resultado mínimo de massa fresca nos potenciais de $-1,23,-0,45$, $-1,50$ e -0,63 MPa, respectivamente (Figura 6). Possivelmente, o decréscimo da disponibilidade de água para as sementes, em função do aumento da concentração de PEG, ocasionou o atraso na expansão e divisão das células, resultando na diminuição da massa fresca. De acordo com Vieira et al. (2013), uma vez que a água desempenha um papel essencial no metabolismo celular, é esperado que as plântulas com maior massa fresca, ou seja, com maior conteúdo de água, possivelmente tenham mais condições de metabolizar suas reservas em energia para o desenvolvimento da plântula.
As plântulas de milheto oriundas das sementes com os teores de água de 14,1\%, 16,1\%, 20,8\% e $21,9 \%$ apresentaram resultados máximos de massa seca nos potenciais de $0,0 \mathrm{MPa},-0,25 \mathrm{MPa},-0,20$ $\mathrm{MPa}$ e -0,22 $\mathrm{MPa}$, respectivamente, de acordo com as equações com elevado ajuste de regressão (Figura 7), indicando que as sementes com o teor de água de $14,1 \%$ foram mais sensíveis à redução dos potenciais hídricos em relação às sementes com os demais teores de água. $\mathrm{O}$ acúmulo de massa seca em condições de estresse hídrico pode ser reduzido devido à falta de água para o metabolismo e à diminuição da velocidade das reações químicas (Marur et al., 1994). $\mathrm{O}$ aumento da massa seca em condições iniciais de estresse hídrico nas sementes com os teores de água acima de $16 \%$ demonstra a habilidade de translocar reservas da semente para o crescimento das plântulas, mediado possivelmente devido à ativação de genes

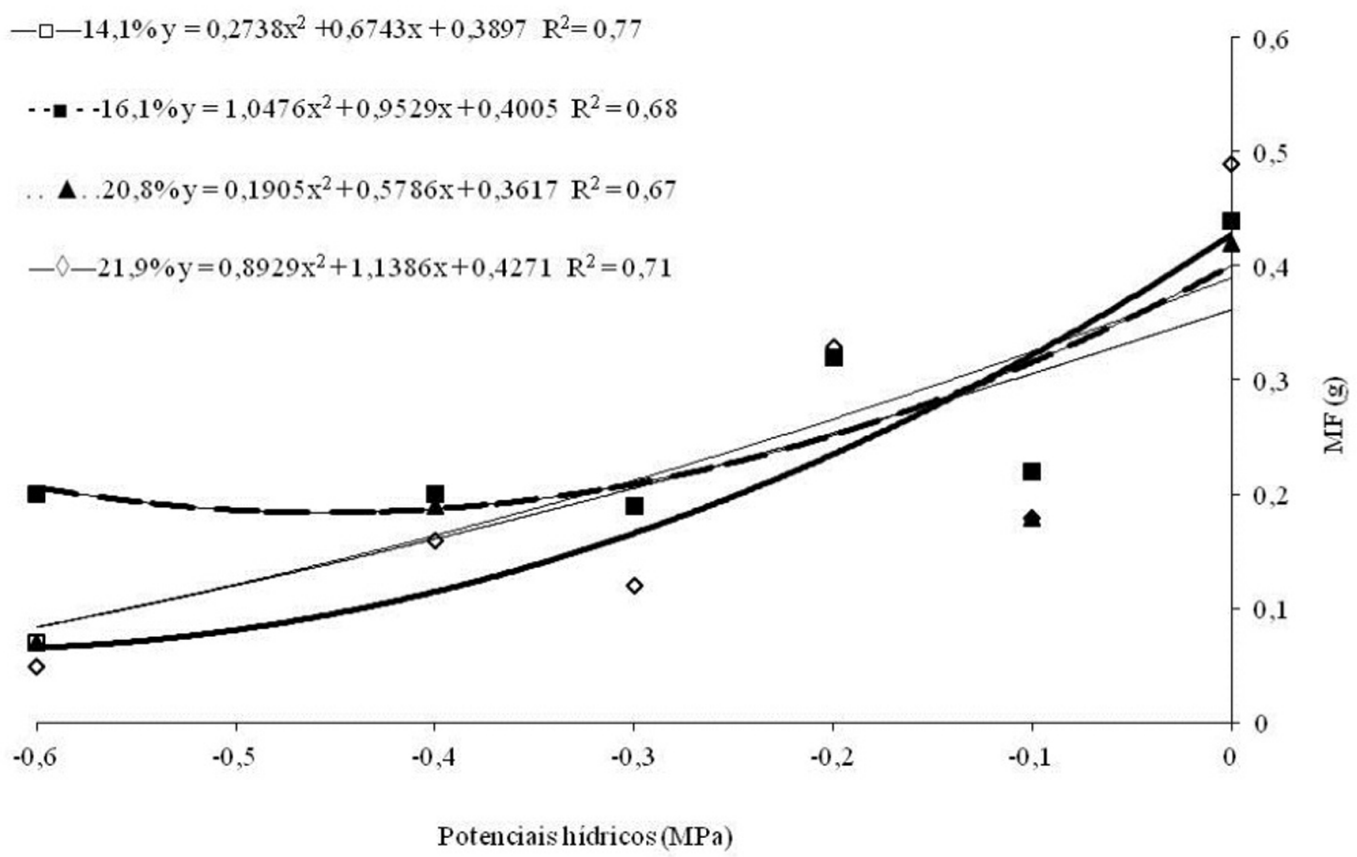

Figura 6. Massa fresca (MF) de plântulas de milheto com teores de água iniciais de 14,5\%, 16,1\%, 20,1\% e 21,9\% submetidas a cinco níveis de potencial hídrico em solução de PEG. Dourados, MS, 2016. 
que proporcionam a síntese de $\mathrm{ABA}$, visando à tolerância da planta em condições de limitações de água (Kholová et al., 2010). Radhouane (2007) verificou que o estresse moderado com PEG (-1,0 MPa) promoveu o aumento do crescimento de raiz de três dos seis ecotipos africanos avaliados e sugeriu que esses resultados refletem uma resposta adaptativa do milheto para alcançar água de locais mais profundos.

Os ajustes fisiológicos durante as fases iniciais da germinação e crescimento da plântula de milheto sob condições de estresse hídrico são variáveis entre as sementes com diferentes teores de água. No entanto, as avaliações da germinação e do crescimento inicial de plantas do milheto sob diferentes disponibilidades hídricas permitem inferir que, embora ocorra diminuição na capacidade de estabelecimento da plântula, determinada pela redução das características de crescimento, essa habilidade é mais sensível em sementes com o teor de água de 14,1\% em relação aos demais teores de água avaliados. Nesse contexto, embora o milheto seja considerado uma planta rústica com elevada adaptação em episódios de baixa disponibilidade hídrica, Lemos et al. (2003) constataram que o milheto semeado na entressafra em região de inverno seco tem seu ciclo e sua produção de matéria seca reduzidos quando da ocorrência de períodos de estiagem, indicando a sensibilidade do crescimento da planta sob estresse hídrico. Nesse contexto, os resultados verificados indicam que, nas fases iniciais da cultura, a diminuição do potencial hídrico determinante na severidade do estresse associado ao teor de água das sementes afetou negativamente a germinação de sementes de milheto e o crescimento inicial de plântulas.

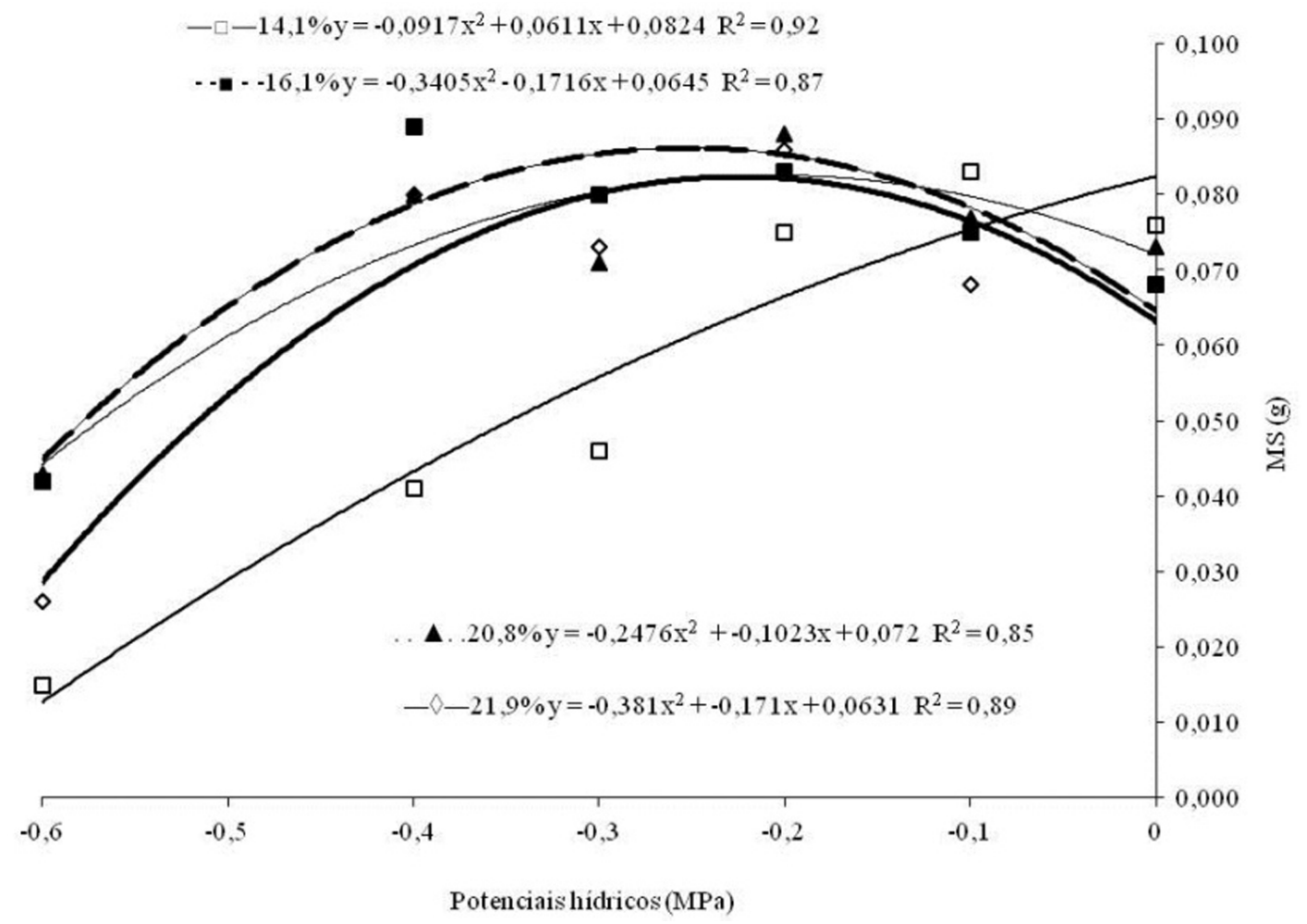

Figura 7. Massa seca (MS) de plântulas de milheto com teores de água iniciais de 14,5\%, 16,1\%, 20,1\% e 21,9\% submetidas a cinco níveis de potencial hídrico em solução de PEG. Dourados, MS, 2016. 


\section{Conclusões}

A redução dos potenciais hídricos do substrato afeta a germinação de sementes com diferentes teores de água e o crescimento das plântulas de milheto. A extensão dos danos no crescimento de plântulas é influenciada pela severidade do estresse hídrico.

\section{Referências}

BERGAMASCHINE, A. F.; FREITAS, R. V. L.; VALÉRIO FILHO, W. V.; BASTOS, J. F. P.; MELLO, S. Q. S.; CAMPOS, Z. R. Substituição do milho e farelo de algodão pelo milheto no concentrado da dieta de novilhos em confinamento. Revista Brasileira de Zootecnia, Viçosa, MG, v. 40, n. 1, p. 154-159, 2011.

DOI: $10.1590 / \mathrm{S} 1516-35982011000100022$.

BEWLEY, J. D.; BLACK, M. Seeds: physiology of development and germination. New York: Prenum Press, 1994. $445 \mathrm{p}$.

BONFIM-SILVA, E. M.; SILVA, T. J. A.; CABRAL, C. E. A.; KROTH, B. E.; REZENDE, D. Desenvolvimento inicial de gramíneas submetidas ao estresse hídrico. Revista Caatinga, Mossoró, v. 24, n. 2, p. 180-186, 2011.

COIMBRA, R. A.; NAKAGAWA, J. Época de semeadura, produção e qualidade fisiológica de sementes de milheto. Revista Brasileira de Sementes, Londrina, v. 28, n. 2, p. 53-59, 2006.

DOI: $10.1590 / \mathrm{S} 0101-31222006000200007$.

CORREIA, K. G.; NOGUEIRA, J. M. C. Avaliação do crescimento do amendoin (Arachis hypogaea L.) submetido a déficit hídrico. Revista de Biologia e Ciências da Terra, Campina Grande, v. 4, n. 2, p. 1-7, 2004. Disponível em: $<$ http://joaootavio.com.br/bioterra/workspace/uploads/ artigos/amendoimdeficit-5156522287e85.pdf>. Acesso em: 15 maio 2016.
DELL'AQUILA, A. Water uptake and protein synthesis in germinating wheat embryos under osmotic stress of polyethylene glycol. Annals of Botany, London, v. 69, n. 2, p. 167-171, 1992.

DOI: 10.1093/oxfordjournals.aob.a088322.

FAGUNDES, J. D.; PAULA, G. M.; LAGO, I.; STRECK, N. A.; BISOGNIN, D. A. Aquecimento global: efeitos no crescimento, no desenvolvimento e na produtividade de batata. Ciência Rural, Santa Maria, v. 40, n. 6, p. 14641472, 2010. DOI: 10.1590/S0103-84782010005000091.

FERREIRA, D. F. Sisvar: a computer statistical analysis system. Ciência e Agrotecnologia, Lavras, v. 35, n. 6, p. 1039-1042, 2011.

DOI: $10.1590 / \mathrm{S} 1413-70542011000600001$.

FORTI, V. A.; CICERO, S. M.; PINTO, T. L. F. Efeitos de potenciais hídricos do substrato e teores de água das sementes na germinação de feijão. Revista Brasileira de Sementes, Londrina, v. 31, n. 2, p. 63-70, 2009.

DOI: $10.1590 / \mathrm{S} 0101-31222009000200007$.

GECHEV, T. S.; DINAKAR, C.; BENINA, M.; TONEVA, V.; BARTELS, D. Molecular mechanisms of desiccation tolerance in resurrection plants. Cellular and Molecular Life Sciences, Basel, v. 69, n. 19, p. 3175-3186, 2012. DOI: $10.1007 / \mathrm{s} 00018-012-1088-0$.

INTERGOVERNMENTAL PANEL ON CLIMATE CHANGE- IPCC. Climate Change 2014: synthesis report. Geneva, 2014. 151 p. Editado por Core Writing Team, R.K. Pachauri e L.A. Meyer. Disponível em: <http://epic.awi. de/37530/1/IPCC_AR5_SYR_Final.pdf $>$. Acesso em: 12 jan. 2015.

KHOLOVÁ, J.; HASH, C. T.; KUMAR, P. L.; YADAV, R. S.; KOCOVÁ, M.; VADEZ, V. Terminal drought-tolerant pearl millet (Pennisetum glaucum (L.) R. Br.) have high leaf $\mathrm{ABA}$ and limit transpiration at high vapour pressure deficit. Journal of Experimental Botany, Lancaster, v. 61, n. 5, p. 1431-1440, 2010. DOI: 10.1093/jxb/erq013.

KUSAKA, M.; LALUSINB, A. G.; FUJIMURA, T. The maintenance of growth and turgor in pearl millet 
(Pennisetum glaucum [L.] Leeke) cultivars with different root structures and osmo-regulation under drought stress.

Plant Science, Limerick, v. 168, n. 1, p. 1-14, 2005.

DOI: 10.1016/j.plantsci.2004.06.021.

LEMOS, L. B.; NAKAGAWA, J.; CRUSCIOL, C. A. C.; CHIGNOLI JÚNIOR, W.; SILVA, T. R. B. Influência da época de semeadura e do manejo da parte aérea de milheto sobre a soja em sucessão em plantio direto. Bragantia, Campinas, v. 62, n. 3, p. 405-415, 2003.

DOI: $10.1590 / \mathrm{S} 0006-87052003000300007$.

MACOVEI, A.; PAGANO, A.; LEONETTI, P.; CARBONERA, D.; BALESTRAZZI, A.; ARAÚJO, S. S. Systems biology and genome-wide approaches to unveil the molecular players involved in the pre-germinative metabolism: implications on seed technology traits. Plant Cell Reports, Berlin, v. 36, n. 5, p. 669-688, 2017.

MASETTO, T. E.; RIBEIRO, D. M.; REZENDE, R. K. S. Germinação de sementes de Urochloa ruziziensis em função da disponibilidade hídrica do substrato e teor de água das sementes. Pesquisa Agropecuária Tropical, Goiânia, v. 43, n. 4, p. 385-391, 2013.

DOI: $10.1590 / \mathrm{S} 1983-40632013000400010$.

MARUR, C. J.; SODEK, L.; MAGAlHÃES, A. C. Free amino acids in leaves of cotton plants under water deficit. Revista Brasileira de Fisiologia Vegetal, Campinas, v. 6, n. 2, p. 103-108, 1994.

MICHEL, B. E.; KAUfMANN, M. R. The osmotic potential of polytylene glycol 6000. Plant Physiology, Bethesda, v. 51, n. 5, p. 914-916, 1973.

DOI: $10.1104 / p p .51 .5 .914$.

OLIVEIRA, A. B.; GOMES-FILHO, E. Germinação e vigor de sementes de sorgo forrageiro sob estresse hídrico e salino. Revista Brasileira de Sementes, Londrina, v. 31, n. 3, p. 48-56, 2009.

DOI: $10.1590 / \mathrm{S} 0101-31222009000300005$.

PENFIELD, S.; MEISSNER, R. C.; SHOUE, D. A.; CARPITA, N. C.; BEVAN, M. W. MYB61 is required for mucilage deposition and extrusion in the Arabidopsis seed coat. The Plant Cell, Rockville, v. 13, n. 12, p. 2777-2791, 2001.

DOI: $10.1105 /$ tpc. 010265 .

PEREIRA FILHO, I. A.; FERREIRA, A. S.; COELHO, A. M.; CASELA, C. R.; KARAM, D.; RODRIGUES, J. A. S.; CRUZ, J. C.; WAQUIL, J. M. Manejo da cultura do milheto. Sete Lagoas: Embrapa Milho e Sorgo, 2003. 17 p. (Embrapa Milho e Sorgo. Circular Técnica, 29).

RADHOUANE, L. Response of Tunisian autochthonous pearl millet (Pennisetum glaucum (L.) R. Br.) to drougnt stress induced by polyethylene glycol (PEG) 6000. African Journal of Biotechnology, Abraka, v. 6, n. 9, p. 1102-1105, 2007.

REGRAS para análise de sementes. Brasília, DF: Ministério da Agricultura, Pecuária e Abastecimento, 2009. 395 p.

SANTOS, A. R. F.; SILVA-MANN, R.; FERREIRA, R. A. Restrição hídrica em sementes de jenipapo (Genipa americana L.). Revista Árvore, Viçosa, v. 35, n. 2, p. 213220, 2011.

DOI: $10.1590 / \mathrm{S} 0100-67622011000200006$.

SILVA, K. R. G.; VILlELA, F. A. Pré-hidratação e avaliação do potencial fisiológico de sementes de soja. Revista Brasileira de Sementes, Londrina, v. 33, n. 2, p. 331-345, 2011.

DOI: $10.1590 / \mathrm{S} 0101-31222011000200016$.

VIEIRA, F. C. F.; SANTOS JÚNIOR, C. D.; NOGUEIRA, A. P. O.; DIAS, A. C. C.; HAMAWAKI, O. T.; BONETTI, A. M. Aspectos fisiológicos e bioquímicos de cultivares de soja submetidos a déficit hídrico induzido por PEG 6000. BioscienceJournal,Uberlândia, v.29,n.2,p.543-552, 2013.

VAZ-DE-MELO, A.; SANTOS, L. D. T.; FINOTO, E. L.; DIAS, D. C. F. S.; ALVARENGA, E. M. Germinação e vigor de sementes de milho-pipoca submetidas ao estresse térmico e hídrico. Bioscience Journal, Uberlândia, v. 28, n. 5, p. 687-695, 2012.

VILLELA, F. A.; DONI-FILHO, L.; SEQUEIRA, E. L. Tabela de potenciais osmóticos em função da concentração 
de polietilenoglicol 6000 e da temperatura. Pesquisa Agropecuária Brasileira, Brasília, DF, v. 26, n. 11/12, p. 1957-1968, 1991.

WATERWORTH, W. M.; BRAY, C. M.; WEST, C. E. The importance of safeguarding genome integrity in germination and seed longevity. Journal of Experimental

Botany, Lancaster, v. 66, n. 12, p. 3549-3558, 2015.

DOI: $10.1093 / \mathrm{j} x \mathrm{~b} / \mathrm{erv} 080$.
YADAV, O. P.; SINGH, M. Prospects of enhancing biomass yield to improve both grain and stover yields of arid zone pearl millet (Pennisetum glaucum L. R. Br.). Euphytica, Wageningen, v. 183, n. 1, p. 11-18, 2012.

DOI: $10.1007 / \mathrm{s} 10681-011-0435-9$. 